http://dx.doi.org/10.5902/1984686X35721

\title{
Caminhos formativos no contexto inclusivo para estudantes com deficiência e outras condições atípicas
}

Training pathways in the integrated context for disabled students and other atypical conditions

\author{
Caminos formativos en el contexto inclusivo para estudiantes con \\ discapacidad y otras condiciones atípicas
}

\section{* Annie Gomes Redig \\ Professora doutora da Universidade do Estado do Rio de Janeiro, Rio de Janeiro, Rio de Janeiro, Brasil. annieredig@yahoo.com.br}

Recebido: 19 de novembro de 2018

Aprovado: 14 de dezembro de 2018

\section{RESUMO}

O presente trabalho, com base em uma revisão da literatura específica da área se propõe a discutir o itinerário formativo e estratégias que podem ser utilizadas para auxiliar no processo de transição da escola para a vida independente de alunos com deficiência. Quando debatemos a política de Educação Inclusiva, um dos desafios é a escolarização de jovens e adultos com deficiência no Ensino Fundamental Il e Médio. Sendo assim, a escola precisa construir metodologias inclusivas que proporcionem a esse educando com deficiência, possibilidades de inserção social e laboral, juntamente com uma escolarização adequada que contemple aspectos voltados para a construção de conhecimentos, desenvolvimento psicossocial e laboral. Nessa direção, acreditamos que com a elaboração de práticas pedagógicas individualizadas atreladas e organizadas por documentos como 0 Plano de Ensino Individualizado (PEI) e Plano Individualizado de Transição (PIT), esse percurso formativo poderá ser construído de forma a possibilitar que a transição da escola para a vida independente aconteça de maneira estruturada e eficiente.

Palavras-chave: Plano de ensino individualizado; Plano individualizado de transição; Inclusão social e laboral.

\section{ABSTRACT}

The present work, based on a review of the specific literature of the area, proposes to discuss the formative itinerary and strategies that can be used to assist in the transition process from school to the independent life of students with disabilities. When we debate the policy of Inclusive Education, one of the challenges is the schooling of young people and adults with disabilities in Primary and Secondary Education. Therefore, the school needs to construct inclusive methodologies that provide this disabled student with possibilities for social and labor insertion, together with adequate schooling that includes aspects related to the construction of knowledge, psychosocial and occupational development. In this 
http://dx.doi.org/10.5902/1984686X35721

direction, we believe that with the elaboration of individualized pedagogical practices linked and organized by documents such as the Individualized Education Plan (IEP) and Individualized Transition Plan (ITP), this training course can be constructed in a way that allows the school transition for independent living to happen in a structured and efficient way.

Keywords: Individualized education plan; Individualized transition plano; Social and work inclusion.

\section{RESUMEN}

El presente trabajo basado en una revisión de la literatura específica del área se propone discutir el itinerario formativo y estrategias que pueden ser utilizadas para auxiliar en el proceso de transición de la escuela a la vida independiente de alumnos con discapacidad. Cuando discutimos la política de Educación Inclusiva, uno de los desafíos es la escolarización de jóvenes y adultos con discapacidad en la Enseñanza Fundamental II y Medio. Por lo tanto, la escuela necesita construir metodologías inclusivas que proporcionen a ese educando con discapacidad, posibilidades de inserción social y laboral, junto con una escolarización adecuada que contemple aspectos orientados a la construcción de conocimientos, desarrollo psicosocial y laboral. En esa dirección, creemos que con la elaboración de prácticas pedagógicas individualizadas acopladas y organizadas por documentos como el Plan de Enseñanza Individualizada (PEI) y el Plan Individualizado de Transición (PIT), ese itinerario formativo podrá ser construido de forma a posibilitar que la transición de la escuela para la vida independiente se produzca de manera estructurada y eficiente.

Palabras clave: Plan de enseñanza individualizada; Plan individualizado de transición; Inclusión social y laboral.

\section{Introdução}

Com o advento da Educação Inclusiva, a escola precisa se preparar, se adaptar para receber alunos com deficiência e outras condições atípicas, portanto, é preciso repensar as práticas pedagógicas para que todos os discentes possam aprender. Um dos desafios da inclusão escolar é a escolarização de pessoas com deficiência intelectual no Ensino Fundamental II e Médio, considerando a condição diferenciada destes no que se refere aos processos de aprendizagem. Apesar de muitos avanços nas últimas décadas em relação ao desenvolvimento de práticas inclusivas nas escolas, ainda vivenciamos uma organização escolar que privilegia a homogeneidade, com foco em procedimentos uniformes tanto no ensino quanto na avaliação. Para atuar no princípio inclusivo, a escola contemporânea necessita proporcionar mais do que apenas o ensino de conteúdos acadêmicos. É fundamental o estímulo e desenvolvimento de habilidades que garantam 
http://dx.doi.org/10.5902/1984686X35721

uma vida independente e autônoma para além do aprendizado formal, tendo como princípio a diversidade humana.

Sendo assim, o objetivo final da escola não deve ser apenas a certificação e em alguns casos, a aprovação em processos seletivos para o ingresso no ensino superior, mas sim precisa possibilitar percursos formativos para que o aluno, principalmente o com deficiência, possa visualizar diferentes caminhos de formação, inserção no mundo do trabalho e na vida adulta. De acordo com Riaño-Galán, Rodríguez-Martín, García-Ruiz, Álvarez-Arregui (2014) esse percurso formativo precisa se configurar como um itinerário personalizado de inserção que contemple as demandas pessoais e promova a inserção social e laboral do sujeito com deficiência, de maneira flexível e abordando as áreas relacionadas com a formação, psicossocial e do trabalho. Desta forma, esse itinerário personalizado de inserção auxiliará o indivíduo oferecendo recursos e serviços adequados às suas características e dificuldades, promovendo igualdade de condições de inserção no mundo do trabalho.

Segundo Lieberman (2003, p. 96) "sem dúvida que o insucesso face um currículo académico limita a escolha e irá afectar a qualidade de vida de um indivíduo. Portanto, o insucesso académico resulta numa desvantagem". Desta forma, o educando com deficiência intelectual devido às dificuldades de aprendizagem que apresenta, acaba ficando em desvantagem em relação aos demais sujeitos.

Ao pensar na escolarização de alunos com deficiência, especialmente os com deficiências intelectual e múltiplas, é fundamental não se limitar apenas às escolas comuns, mas precisamos pensar também nas instituições especializadas como uma opção para essa população, principalmente, para os mais comprometidos e/ou com idade avançada. Não estamos aqui para defender qual espaço de escolarização é ideal para eles, mas sim, acreditamos que todos os ambientes podem e devem proporcionar aprendizado.

De acordo com Rebelo e Kassar (2018, p.291)

O número de matrículas de alunos da Educação Especial [em escolas comuns] aumentou em todas as regiões no período de 2007 a 2014. Considerando o foco da política educacional de universalização da educação no país, esse aumento é promissor, todavia insuficiente para conhecer as condições da escolarização desses alunos no sistema escolar como permanência, participação e desempenho (LAPLANE, 2015). Diferentemente de sucesso, trabalhos acadêmicos têm evidenciado limitações do funcionamento da escola quanto ao desenvolvimento acadêmico dessa população, com a identificação dos seguintes problemas: concentração de matrículas nas primeiras séries do ensino fundamental (MELETTI; RIBEIRO, 2014), pouco acesso ao conhecimento sistematizado (CARVALHO; 
http://dx.doi.org/10.5902/1984686X35721

PLETSCH, 2013) e pouco acesso ao atendimento educacional especializado (REBELO, 2012).

A matrícula de estudantes com deficiência na turma comum não é sinônimo de aquisição de conhecimento, de aprendizado, visto que, alguns são aprovados na série, mas sem o desenvolvimento acadêmico esperado para 0 ano de escolaridade cursado. $A$ situação fica ainda mais desafiadora quando esses educandos chegam ao Ensino Fundamental II e Médio.

Nessa direção, com base em uma revisão sistemática da literatura específica da temática, o presente trabalho pretende debater como a escola pode repensar suas práticas pedagógicas e o processo de transição da escola para vida independente, ou seja, uma formação capaz de auxiliar o aluno com deficiência intelectual para o momento pós-escola.

Discutir a transição da escola para a vida independente é essencial, principalmente no que tange aos jovens e adultos com deficiência intelectual, pois se para os jovens que não possuem deficiência esse período é complicado, para esses, a situação é mais complexa. Segundo Almeida (2014, p.387)

\begin{abstract}
A transição da escola ao mundo do trabalho e o próprio processo de inserção profissional dos jovens transformou-se numa fase intermédia, num tempo de moratória, "num verdadeiro percurso do combatente" (CHARLOT; GLASSMAN, 1998, p. 21). É um dos principais problemas com que se debate a juventude contemporânea, sendo eleito para a intervenção pelos poderes públicos através de medidas de política de educação e formação profissional, de emprego e de juventude.
\end{abstract}

Outro ponto que Almeida (2014) levanta é que a "entrada na vida adulta" está marcada pelo fim de uma etapa e início de outra, como fim dos estudos, início da vida profissional, a saída de casa, construção de uma nova família. Contudo, para a grande parte das pessoas com deficiência intelectual a "entrada na vida adulta, independente e mundo do trabalho", infelizmente, não é tão natural quanto para os demais, visto que, em alguns casos, esses sujeitos nem saem da escola, não havendo então, o fim de uma etapa. Para Lopes (2016, p.58) "A transição para a vida adulta é parte de uma etapa significativa da vida de uma pessoa, e cada passo precisa ser orientado de forma adequada para a obtenção de bons resultados e garantia de qualidade de vida para os jovens com DI [deficiência intelectual]".

Fânzeres (2017) aponta que a transição é um processo de ressignificação dos papéis desempenhados, no aprendizado de novas funções e modificações dos existentes, configurando um desafio para o sujeito tanto no entendimento da sua existência quanto no lidar com novas metas, planos e barreiras impostas pela sociedade. 
http://dx.doi.org/10.5902/1984686X35721

As pessoas com deficiência, principalmente com deficiência intelectual, demandam uma preparação para enfrentar os desafios de uma vida adulta, autônoma e inclusiva, onde se faz necessário desenvolver competências essenciais à participação em diferentes ambientes, assim como capacitá-los nas áreas do desenvolvimento pessoal e social e da adaptação ao meio laboral (CARVALHO, 2018, p.49).

Portanto, é imprescindível para os jovens e adultos com deficiência intelectual que haja programas na escola que estimulem estratégias para que a transição da escola para a vida independente aconteça de forma eficiente para que o momento pós-escola seja realmente o início da vida adulta, englobando assim, os direitos e deveres dessa fase. Preferimos denominar este momento não como transição da escola para vida adulta e mundo do trabalho, mas sim para a vida independente, no qual contempla aspectos para além da inserção profissional. Desta forma, o presente artigo, por meio de levantamento bibliográfico e de forma conceitual, pretende discutir algumas estratégias pedagógicas que a escola pode utilizar para facilitar esse processo para os alunos com deficiência, em especial, os com deficiência intelectual.

\section{A inclusão escolar e os desafios na escolarização do estudante com deficiência}

De acordo com a Política Nacional de Educação Especial na perspectiva da Educação Inclusiva (BRASIL, 2008) para implementação da escola inclusiva, todos os alunos com deficiência, inclusive intelectual, devem estar matriculados em turmas comuns, recebendo uma complementação pedagógica do Atendimento Educacional Especializado (AEE), por meio do suporte do professor especialista, prioritariamente em uma sala de recursos, no turno inverso à sua escolarização.

A legislação nacional sobre a implantação do AEE na modalidade de sala de recursos orienta sobre os objetivos deste serviço, assim como dá diretrizes para sua operacionalização nas escolas. Entretanto, não há instruções efetivas sobre como deve ser efetivado no cotidiano escolar para favorecer o processo de inclusão dos alunos com base em um trabalho colaborativo com todos os profissionais envolvidos neste processo (BRASIL, 2009, 2011).

E, ainda há o desafio apontado por Rebelo e Kassar (2018, p. 297-298) no que concerne a avaliação deste serviço, pois "considerando que o número de matrículas não designa necessariamente o número de alunos nas escolas, devido às duplas matrículas, de fato não se sabe ao certo qual foi o avanço da escolarização da população-alvo da 
Educação Especial no período". Se analisarmos a estatística de alunos com deficiência intelectual que entraram e saíram da escola, não saberíamos dizer, apesar da certificação, se a escolarização foi adequada de acordo com a idade e série. O diploma de conclusão do Ensino Médio, por exemplo, não garante a colocação desse sujeito no mercado de trabalho, sua manutenção no emprego e inserção na vida adulta com autonomia e independência.

Lieberman (2003) lembra que alguns sujeitos com deficiência intelectual não são considerados competentes em termos acadêmicos e consequentemente, resultam em fracasso escolar, apresentando uma desvantagem na escola e na vida em comparação com os demais estudantes que conseguem se "dar bem" na escola, fazendo com que o fracasso / insucesso escolar se transforme em fracasso / insucesso na vida. Desta forma, é necessário um trabalho no contexto escolar que valorize outras competências e aptidões desses alunos para que consigam se incluir socialmente e ter uma adequada transição para a etapa da vida adulta.

Por isso, é importante que o AEE, seja no formato de sala de recursos multifuncional, mediação escolar, ensino colaborativo, entre outros, garanta os suportes necessários para uma escolarização adequada, centrada no estudante. Para isso, os professores da Educação Especial em parceria com os demais docentes e profissionais que atendem 0 aluno com deficiência, devem trabalhar colaborativamente para o desenvolvimento das potencialidades do sujeito.

De acordo com a Política de Educação Especial e Inclusiva (BRASIL, 2008, p.11), o AEE tem como função

identificar, elaborar e organizar recursos pedagógicos e de
acessibilidade que eliminem as barreiras para a plena participação dos
estudantes, considerando suas necessidades específicas. As
atividades desenvolvidas no atendimento educacional especializado
diferenciam-se daquelas realizadas na sala de aula comum, não sendo
substitutivas à escolarização. Esse atendimento complementa e/ou
suplementa a formação dos estudantes com vistas à autonomia e
independência na escola e fora dela.

$\mathrm{Na}$ citação acima fica evidente a importância do AEE para o processo de ensinoaprendizagem do educando com deficiência e que esse serviço não se limita ao suporte para as atividades acadêmicas, mas a formação do sujeito para além dos muros da escola, ou seja, para sua inclusão social e laboral.

A Lei Brasileira de Inclusão (BRASIL, 2015) no capítulo IV, artigo 28, inciso V preconiza a "adoção de medidas individualizadas e coletivas em ambientes que maximizem 
http://dx.doi.org/10.5902/1984686X35721

o desenvolvimento acadêmico e social dos estudantes com deficiência, favorecendo o acesso, a permanência, a participação e a aprendizagem em instituições de ensino". Partindo deste princípio, a escola pode flexibilizar o currículo para o estudante com deficiência intelectual, a partir de metodologias inclusivas e Plano de Ensino Individualizado (PEI).

Para isso, é preciso entender as práticas pedagógicas desenvolvidas pelos docentes para compreender o aprendizado desses educandos e assim construir estratégias diferenciadas de ensino. De acordo com Pletsch e Glat (2013) para diferenciar as práticas pedagógicas é fundamental rever os aspectos que contemplam o currículo escolar, planejar as aulas com base em avaliações educacionais sobre o processo de aprendizagem dos educandos. Lieberman (2003, p.92) coloca que muitos alunos considerados normais não apresentam sucesso na escola, pois não são "tratados ou ensinados recorrendo a métodos diferenciados. Se os alunos são diferentes, aprendem de forma diferente também". Mascaro (2017, p. 36), destaca que

O processo inclusivo não pode estar associado a um padrão de modelo único, pois os estudantes não apresentam diferenças no seu processo de aquisição de conhecimentos que possam ser atendidas de uma mesma forma, ou seja, por meio de uma única proposta de apoio.

O PEI é um instrumento utilizado para a individualização do ensino, construído com a comunidade escolar, demais profissionais, familiares e o próprio aluno, um programa com metas acadêmicas e sociais que atendam às necessidades e singularidades do sujeito (GLAT, 2012; GLAT; PLESTSCH, 2012; GLAT, VIANNA; REDIG, 2012; MASCARO, 2017), que organiza as propostas pedagógicas elaboradas de acordo com as necessidades e capacidades do aluno com deficiência (MASCARO, 2017). Esse é documento importante para garantir uma escolarização significativa para os estudantes com deficiência intelectual e com estratégias para o desenvolvimento de habilidades para o momento pós-escola. 0 PEI precisa contemplar metas acadêmicas, sociais e laborais.

Para o desenvolvimento do PEI é necessário que a família, professores e demais profissionais estejam envolvidos e que o próprio aluno também participe da elaboração e construção deste instrumento, é claro que com contribuições de acordo com a sua faixa etária. Porém, essa participação é fundamental para que o PEl atenda as necessidades do educando e contemple suas habilidades.

Como já citado o PEl deve englobar também como meta a inclusão social e laboral do sujeito com deficiência. Portanto, um dos eixos deste documento que discutiremos é o 
http://dx.doi.org/10.5902/1984686X35721

Plano Individualizado de Transição (PIT), esse é um instrumento que auxiliará a equipe do PEI a pensar estratégias para o desenvolvimento de competências para que o aluno com deficiência intelectual possa escolher e definir suas ações futuras quando sair da escola.

Práticas pedagógicas em que aproximem o aluno à realidade de sua comunidade, com metas bem definidas, possibilitam a sua inclusão social, o que só poderá ser proporcionado por meio de atividades individualizadas que contemplem suas necessidades e privilegiem suas aptidões.

\section{O Plano Individualizado de Transição como uma ferramenta para a inclusão social de pessoas com deficiência}

Muito se discute a inclusão escolar de alunos com deficiência, em particular os que possuem deficiência intelectual, mas pouco se debate sobre o momento pós-escola, ou seja, qual caminho esses sujeitos poderão seguir quando finalizarem seus estudos no ensino comum? A escola precisa ser um espaço de transformação, um ambiente promissor ao desenvolvimento de habilidades para a vida e da oferta de diversas opções de futuro, por isso, a importância do PIT.

O PIT é um documento para organizar o processo de transição do aluno com deficiência da escola para a vida adulta e/ou mundo do trabalho, vida independente, sendo um dos eixos do PEI. Desta forma, esse processo será organizado por uma equipe, a mesma do PEI, incluindo, obrigatoriamente, o aluno. Soriano (2006, p.24) conceitua o PIT como

\footnotetext{
Um instrumento, uma ferramenta, sob a forma de documento, no qual é registrado o passado, o presente e o futuro desejado dos jovens. Ele deve incluir informação sobre o universo da vida do jovem: condições familiares, histórico médico, tempos livres, valores e background cultural, e ainda informação sobre a sua educação e formação.
}

Nos EUA, em alguns estados americanos, esse planejamento pode iniciar a partir dos 16 anos de idade, mas como aqui no Brasil nós temos a atividade do "jovem aprendiz", acreditamos que o planejamento do PIT pode começar aos 14 anos de idade, se houver necessidade pode ser antes, para que o estudante possa se conhecer e desenvolver as habilidades necessárias para a sua inserção em atividades laborais. Para Trainor (2017) precisamos mudar a proposta de planos de transição para uma transição na educação, no qual isso fará parte da política educacional. Não terá apenas o objetivo de dominar / adquirir requisitos para o trabalho, mas a oferta de suportes e serviços para a área / modalidade da 
http://dx.doi.org/10.5902/1984686X35721

transição. Segundo a autora, esse é um conceito mais holístico, no qual considera aspectos da vida adulta e não apenas o trabalho.

O período que compreende o fim da adolescência e entrada na vida adulta é
um marco tanto para o indivíduo, quanto para sua família. Entretanto, esta é
uma fase difícil para as pessoas com deficiência, e, na maioria das vezes, os
pais não têm expectativa de que seus filhos se tornem economicamente
ativos. Para que a transição para a vida adulta e possível ingresso no
mercado de trabalho de jovens com deficiência seja menos conflituosa e
estressante, é importante a elaboração de metas educacionais e um currículo
flexível. (REDIG; MASCARO; ESTEF, 2016, p.6)

Trainor (2017) aponta que a colocação de pessoas com deficiência no mercado de trabalho após o término do Ensino Médio, não garante a permanência deste sujeito no emprego. Por isso, é fundamental que o PIT seja planejado, elaborado e implementado em equipe, com o aluno e, de forma que atenda os interesses dele. Não é para planejar metas para alcançar uma profissão e emprego específicos, mas sim, o propósito é o desenvolvimento de habilidades sociais e laborais para que o sujeito possa entrar e se manter no trabalho de forma satisfatória e com qualidade.

Então, para a construção do PIT é preciso considerar os aspectos da vida do sujeito e posteriormente da fase adulta, como laços com a comunidade, atividades fora da escola, entre outros. Sendo assim, não podemos apenas pensar no trabalho, mas também nos aspectos da vida do sujeito, nos aspectos psicossociais (TRAINOR, 2017). Devemos, então, utilizar um inventário de habilidades para o planejamento do processo de transição que possibilite o conhecimento e habilidades do aluno referente à comunicação, conteúdos acadêmicos, participação da comunicação, etc.

Para organizar esse inventário e consequentemente elaborar o PIT, podemos utilizar o conceito do Perfil Pessoal Positivo (PPP) (REDIG, 2012, 2014, 2016), que consiste na utilização de um inventário de habilidades, com o objetivo de visualizar as capacidades e potencialidades do sujeito (LUECKING, 2012). Sendo assim, pode-se "transformar / ressignificar" características negativas em positivas, como por exemplo, a hiperatividade em energia (MARTIN-LUECKING, 2012). A ênfase nas características positivas das pessoas com deficiência tem a finalidade de reforçar, por parte dos empregadores, a noção de que todos podem trabalhar. Na construção do PPP, é importante destacar as qualidades do indivíduo, ao invés do que ele não pode realizar, como acontece, muitas vezes na escola (tanto especial quanto regular) (REDIG, 2012, 2014, 2016).

Todavia, para a aplicação do PPP, o aluno precisa se conhecer. Trainor (2017) aponta que o PIT exige que os alunos com deficiência; no caso enfatizamos o estudante com 
http://dx.doi.org/10.5902/1984686X35721

deficiência intelectual, tenha conhecimento dos pontos fortes e fracos, das dificuldades e capacidades, para assim, articular com seus objetivos, experiências e aprendizados, com a finalidade de reconhecer seu progresso. O conhecimento das competências do aluno não é só importante para o próprio estudante, mas também para o professor, pois "a qualidade do ensino que você proporciona aos seus alunos está intrinsecamente ligada ao quão bem você conhece as capacidades e personalidade deles" (VALLE; CONNOR, 2014, p.100).

Lieberman (2003, p.96) coloca que "existem muitas formas significativas de alcançar uma qualidade de vida que vá coincidir com os desejos pessoais, as quais pouco ou nada têm a ver com o desempenho académico". Por isso, é fundamental que o aluno com deficiência intelectual e a família estejam cientes e participem da construção e implementação do PIT, para que todos tenham consciência do que foi planejado e estipulado no documento e consequentemente para as metas colocadas para o período após a escola. Isso favorece a autoestima do sujeito e seu aprendizado, pois ele estará envolvido com o processo de ensino-aprendizado, de forma a relacionar seus interesses e desejos com os conteúdos das disciplinas. Para Lieberman (2003, p.97) quando o aluno não aprende "a auto-estima e a autoconfiança são severamente atacadas e as consequências do insucesso escolar podem, de facto, persistir até a velhice".

Vale lembrar que para a implementação do PIT, o suporte da Educação Especial, o AEE, deve estar conciso com esse processo, visto que, será este profissional a peça chave para o sucesso da transição. Acreditamos que será durante o AEE que o aluno com deficiência vivenciará experiências para além do aprendizado acadêmico e que proporcione o desenvolvimento de habilidades sociais e laborais, por exemplo, por meio de estágios e treinamentos realizados na própria escola.

\begin{abstract}
A escola não tem que se restringir ao aspecto académico. Pode contemplar uma grande variedade de outros aspectos. Se os alunos têm sucesso em áreas não académicas, a sua auto-estima, motivação, ambição e luta por escolhas pessoais permanecerão intactas. Podem ter sucesso na escola, mas não necessariamente numa escolaridade académica. (LIEBERMAN, 2003, p.97)
\end{abstract}

O AEE precisa se reorganizar para a aplicação do PEI e consequentemente do PIT, pois não há condições que o professor especialista auxilie no desenvolvimento de habilidades sociais e laborais, com um número elevado de alunos com deficiência na sala de recursos multifuncional, por exemplo, especialmente porque esse serviço deve ser prestado no formato individual. Para a implementação de atividades do PIT, o docente 
http://dx.doi.org/10.5902/1984686X35721

necessitará de tempo de planejamento das ações e de diálogo com os demais envolvidos no processo, além de carga horária maior para o atendimento dos educandos.

Os serviços e suportes especializados auxiliarão na definição das necessidades do educando com deficiência intelectual, pois isso é a essência do que é especial na Educação Especial. É função dos programas e serviços especializados proporcionar / ensinar estratégias para os indivíduos com deficiência intelectual a organizar a vida e desenvolver competências adaptativas, além de atividades da vida diária (LIEBERMAN, 2003). Por isso, o AEE é fundamental para a implementação das ações do PIT

\section{Pensando o Plano Individualizado de Transição}

Como já discutido o PIT faz parte do PEI e por isso deve ser elaborado por uma equipe e deve utilizar as informações que já existem, como as entrevistas com os pais, alunos e demais profissionais, relatórios, notas e desempenho acadêmico, cursos realizados, competências e habilidades. Para a construção do PIT é preciso valorizar o que o estudante com deficiência já sabe, as suas capacidades e interesses e não as suas dificuldades.

Nessa direção, é preciso compreender: 1) Onde o aluno está hoje; 2) Para onde ele irá e 3) Como o aluno chegará lá. Por isso, a coleta das informações é fundamental, pois o PIT contemplará os pontos fortes, preferências, interesses e necessidades, apontadas no PPP do aluno. Desta forma, poderemos pensar nas estratégias para a educação, treinamento, capacitação do estudante, nas atividades laborais e habilidades para a vida independente. Esse instrumento auxiliará no autoconhecimento do indivíduo com deficiência para que seja capaz de reconhecer suas qualidades, o que faz bem, seus interesses e assim, estabelecer estratégias para alcançar suas metas, identificar conexões com a comunidade e entender a sua deficiência.

O PIT é um plano conduzido pelo sujeito com deficiência, com a finalidade de maximizar o seu desempenho e estabelecer metas no ensino que levarão ao sucesso no momento pós-escola, pois será preciso combinar experiências de vida, sociais e laborais com os conhecimentos acadêmicos. Portanto, os professores precisam aumentar as expectativas depositadas nos alunos com deficiência intelectual.

Redig, Mascaro e Estef (2016) enfatizam a necessidade da avaliação contínua do PEI e PIT, pois o êxito desse processo é a qualidade da avaliação do processo. Esse instrumento precisa conter objetivos de médio e longo prazos, de acordo com a idade do 
http://dx.doi.org/10.5902/1984686X35721

discente e é necessário observar se as metas são condizentes com os interesses, aptidões e desenvolvimento do aluno.

Essa ação é essencial para o desenvolvimento da ação docente e do processo de ensino-aprendizagem do aluno com deficiência. Sendo assim, a partir dessa avaliação, novas estratégias e metas podem ser pensadas, garantindo assim a construção do conhecimento e a elaboração de metodologias inclusivas. (REDIG; MASCARO; ESTEF, 2016, p.11)

De acordo com um documento elaborado pelo Center on Transition Innovations (CTI, 2018a) da Virginia Commonwealth University, informa que, os dez indicativos de sucesso no processo de transição são: 1) inclusão; 2) diploma / certificação; 3) experiência de trabalho remunerado (pode ser ainda na escola); 4) habilidades de vida independente e autocuidado; 5) suporte ao estudante com deficiência (enfatizamos o serviço do AEE); 6) programa de transição; 7) autogestão; 8) habilidades sociais 9) orientação vocacional / orientação para carreira, trabalho e 10) envolvimento dos responsáveis. desenvolvimento de apenas uma ou duas dessas áreas, não garantirá o suporte necessário para que o jovem e adulto com deficiência consiga as habilidades necessárias para a transição da escola para a vida independente. Por isso, é importante o investimento em políticas públicas, formação de professores e práticas pedagógicas diferenciadas nas dez áreas.

Desta forma, o PIT é um documento para organizar e direcionar o plano educacional e as atividades de carreiras do aluno com deficiência. Sendo assim, este plano precisa conter os seguintes aspectos:

- Iniciar aos 14 anos de idade;

- Interesses, desejos, aptidões do sujeito;

- Plano acadêmico e de carreira;

- Alinhar o curso de estudo com os objetivos laborais. Interesses acadêmicos e profissionais;

- Planejar atividades educacionais e laborais;

- $\quad$ Plano assinado pelo estudante, família e professores;

Para a elaboração e implementação do PIT, como já discutido, os suportes são fundamentais para esse processo e há necessidade de enfatizar o papel da Educação Especial, no formato de AEE no ensino comum e de professores especializados nas escolas e classes especiais para que realmente a transição da escola para uma vida independente aconteça de fato. O PIT deve ser parte essencial do PEI e consequentemente do Plano de AEE. Sem isso, provavelmente a transição não terá êxito, pois é por meio 
http://dx.doi.org/10.5902/1984686X35721

desses serviços que o aluno terá oportunidade para o aprendizado de conteúdos que estão fora do contexto acadêmico, como atividades da vida diária, plano financeiro, manutenção e limpeza da casa, utilização do transporte público, organização do tempo, relacionamento, regras sociais, pensamento crítico e autogestão.

Vale lembrar que o objetivo final do programa de transição deve ser capacitar o sujeito com deficiência para uma vida independente. Entretanto, há que se observar que vida independente, não necessariamente, significa ser uma pessoa que não precisa de suporte, visto que, ninguém é $100 \%$ independente. O que pretendemos alcançar é que o jovem e adulto com deficiência intelectual seja capaz de viver de uma forma mais independente e autônoma possível. Para isso, precisamos considerar alguns aspectos como lazer, recreação, manutenção da casa, cuidados pessoais, participação na comunidade e cidadania (CTI, 2018b).

Carvalho (2018) coloca que esse momento de transição é uma fase difícil para todos os jovens, pois é repleta de tomada de decisões referentes ao seu futuro. Os docentes precisam auxiliar seus educandos a selecionar as opções que se enquadram nos seus objetivos e necessidades, que pode ser um curso técnico, de formação inicial e continuada, ensino superior, entre outros, como apontado na Lei Brasileira de Inclusão (BRASIL, 2015). Porém, os estudantes é que devem decidir qual caminho seguir e para isso é necessário: perceber seus objetivos; estabelecer seus planos; tomar uma atitude / plano de ação; avaliar seu progresso (CTI, 2018a). Sendo assim, um trabalho voltado para orientação vocacional, desenvolvimento de habilidades laborais e sociais e, conhecimento de carreira que contemple treinamento, estágios, etc, é fundamental para esse processo.

Nesse sentido, é dever dos professores instrumentalizar os alunos com deficiência para a tomada de decisões, de forma a criar oportunidades para escolhas, decisões, resolução de problemas e autogestão (CTI, 2018a). Essas são áreas de dificuldade para os educandos com deficiência intelectual, por isso, é necessário que seja trabalhado desde a Educação Infantil. Outros aspectos que merecem ser enfatizados são o envolvimento dos responsáveis nesse processo, pois a família é fundamental no desenvolvimento do PIT e de habilidades para uma vida independente, além da avaliação contínua do processo e da participação ativa do sujeito com deficiência na elaboração e implementação do PIT.

\section{A inserção de pessoas com deficiência em atividades laborais}


http://dx.doi.org/10.5902/1984686X35721

Desde 1991, com a criação da Lei de Cotas (BRASIL, 1991) há crescimento da inserção de pessoas com deficiência no mercado de trabalho, mas infelizmente, esse número ainda não é suficiente, principalmente no que se refere aos sujeitos com deficiência intelectual, pois ainda há muitas barreiras a serem vencidas (REDIG, 2014, 2016). Um dos empecilhos colocados pelos empregadores é a escolarização mínima e capacitação. Por isso, o processo de transição é importante para a colocação desses indivíduos em atividades laborais.

Para que a família e a pessoa com deficiência intelectual possam pensar no momento pós-escola e inserção no mundo do trabalho, é necessário que a escola desde muito cedo, aponte as qualidades e capacidades deste aluno, estimulando o desejo e possibilidade de trabalhar no futuro. Então, os professores devem se concentrar na vontade de trabalhar dos educandos com deficiência e discutir com eles suas dificuldades, interesses e quais suportes poderão ser utilizados para tornar o ambiente acessível (CTI, 2018a). A Lei Brasileira de Inclusão (BRASIL, 2015) no artigo 34 preconiza que "a pessoa com deficiência tem direito ao trabalho de sua livre escolha e aceitação, em ambiente acessível e inclusivo, em igualdade de oportunidades com as demais pessoas", além de ter acesso a treinamentos, promoções, planos de carreiras, etc.

$\mathrm{Na}$ construção do PIT no que se refere ao desenvolvimento de habilidades laborais e conhecimento de carreiras é preciso ter claro que ter interesse em uma área não é suficiente, é necessário ter conhecimento específico na área e relacionar esse interesse às experiências laborais, sociais e disciplinas acadêmicas (CTI, 2018a). Para isso, os cursos de formação, treinamentos e estágios são estratégias para 0 aprofundamento e aprendizagem de conteúdos.

Mais uma vez chamamos atenção aos suportes que serão oferecidos tanto no processo de transição quanto no trabalho, pois sem eles, dificilmente o sujeito com deficiência intelectual conseguirá se manter no emprego. A escolha da carreira e/ou função laboral requer exploração, experiência e descoberta e para isso será necessário (CTI, 2018a):

- Explorar e proporcionar experiências e descobertas laborais;

- Aprendizado em local de trabalho;

- Combinar experiência acadêmica com os interesses de carreiras.

$\mathrm{O}$ aprendizado baseado no trabalho oferece a oportunidade de aprender enquanto se desenvolve habilidades laborais no próprio local de trabalho, a partir de uma atividade 
http://dx.doi.org/10.5902/1984686X35721

específica. Essas experiências podem ser remuneradas ou não, o importante é possibilitar oportunidades de treinamento e capacitação com a finalidade de identificar interesses de carreira, avaliar as habilidades de empregabilidade e as necessidades de formação (CTI, 2018a).

Partindo deste princípio, a customização de atividades laborais ou emprego customizado vem de encontro com estes conceitos (REDIG, 2013, 2014, 2016; REDIG; GLAT, 2017).

De acordo com Luecking (2011), o trabalho customizado é o resultado da reestruturação ou criação de atividades em um posto de trabalho, visando à inclusão de pessoas com deficiência que, de outra forma, não poderiam ser contratadas. Este processo exige, contudo, a avaliação das habilidades e potencial de aprendizagem do futuro trabalhador e as possibilidades de adequação do ambiente de trabalho. (REDIG; GLAT, 2017, p.11)

A customização de atividades laborais será o resultado de toda coleta das informações, análise e avaliação do processo de transição desse jovem e adulto, tornando assim, a inserção do indivíduo com deficiência no mercado de trabalho eficaz e satisfatória tanto para o empregador quanto para o empregado. Redig (2016, p.205) lembra que "analisar o ambiente de trabalho com o objetivo de refletir sobre a verdadeira necessidade de mão de obra é fundamental para a inclusão e para a contratação das pessoas com deficiências nas empresas".

Nessa direção, é preciso ressaltar que durante o planejamento e aplicação do PIT os envolvidos no processo devem estar cientes das metas propostas e estratégias que serão utilizadas para que a sua futura inserção no mercado de trabalho, seja pelo emprego competitivo tradicional ou customizado, tenha o viés da empregabilidade e permanência na empresa. Outro aspecto que deve ser levado em conta é o interesse e necessidade do empregador na criação de uma função e contratação deste funcionário, pois caso contrário, essa relação de custo x benefício não dará certo. Por isso, o engajamento da família, do aluno e a conexão com a comunidade são importantes para a descoberta de possibilidades de trabalho.

\section{Considerações Finais}

Diante do exposto cabe ressaltar que a reconfiguração do modo de organização das nossas escolas é imperativo para que avancemos na constituição da escola dos dias atuais, a escola inclusiva. Uma escola que se preocupe com a diversidade dos estilos e ritmos de aprendizagem, e tenha atenção aos motivos intrínsecos ou extrínsecos que impedem determinados alunos de aprender. 
http://dx.doi.org/10.5902/1984686X35721

Dentre as muitas facetas da exclusão em nossas escolas nos dias de hoje, encontrase a dificuldade para inserir em seu cotidiano os alunos que apresentam uma deficiência intelectual. Para um adequado processo formativo, cabe o trabalho pedagógico com base na individualização por meio da elaboração do PEI e consequentemente do PIT. É necessário reconhecer esses sujeitos como capazes de produzir conhecimento, a partir da organização de um trabalho onde a ação e interação favoreçam o desenvolvimento de potenciais diversos, além daqueles valorizados até então pela nossa escola (conteúdos acadêmicos formais). Sendo assim, dentro de um amplo universo de mudanças necessárias na escola, apontamos como adequado para estudantes com deficiência e em especial os com deficiência intelectual que, embora heterogêneos, apresentam uma necessidade em comum, que é o apoio diferenciado para o seu desenvolvimento acadêmico e inclusão social. O trabalho com o PEI e o PIT permitirá planejar, desenvolver atividades específicas, flexibilizar o currículo e avaliar o desenvolvimento destes estudantes favorecendo a inclusão social dos mesmos.

\section{Referências}

ALMEIDA, Maria Sidalina. A transição da escola para o mundo do trabalho constituída em objecto de estudo: uma abordagem teórico-metodológica. Caderno Cedes. v. 34, n. 94, p. 385-400. Campinas, 2014. Disponível em: http://www.scielo.br/pdf/ccedes/v34n94/0101-3262-ccedes-34-94-0385.pdf Data de acesso 10/10/2018.

BRASIL. Lei 8.213, de 24 de julho de 1991.

BRASIL. Política Nacional de Educação Especial na Perspectiva da Educação Inclusiva. 2008.

BRASIL. Resolução n. 4 de outubro de 2009. 2009.

BRASIL. Decreto 7611 de 17 de novembro de 2011. 2011.

BRASIL. Lei Brasileira de Inclusão no 13.146, de 6 de julho de 2015. 2015.

CARVALHO, Ana Cristina de. Plano Individual de Transição para vida adulta para pessoas com deficiência intelectual. Dissertação do Curso de Mestrado Profissional em Diversidade e Inclusão. Niterói, UFF, 2018.

CTI, Center on Transition Innovations. Lesson Four Transcript. Postsecondary Education \& Training: Opening Doors to Opportunities. Virginia, 2018a. 
http://dx.doi.org/10.5902/1984686X35721

CTI, Center on Transition Innovations. Lesson Three Transcript. Competitive Employment: Preparing for the 21st Century Workforce". Virginia, 2018b.

FÂNZERES, Luis José Leite Teixeira. Transição para a vida adulta de alunos com necessidades educativas especiais: percursos de formação no sistema educativo Português. Tese do Curso de Doutorado do Instituto de Educação da Universidade do Minho. Portugal, 2017.

GLAT, Rosana. A Educação Especial no contexto da Educação Inclusiva: diretrizes políticas e ações pedagógicas. Relatório Científico do projeto CNPQ 2010-2012. Rio de Janeiro, 2012.

GLAT, Rosana; PLETSCH, Márcia Denise. Inclusão escolar de alunos com necessidades especiais. Rio de Janeiro: EdUERJ, 2012.

GLAT, Rosana; VIANNA, Márcia Marin; REDIG, Annie Gomes. Plano Educacional Individualizado: uma estratégia a ser construída no processo de formação docente. Ciências Humanas e Sociais em Revista, p. 79-100, v. 34, n. 12. 2012.

LIEBERMAN, Laurence M. Preservar a Educação Especial... Para aqueles que dela necessitam. In: CORREIA, L. de M. (Orgs.). Educação Especial e Inclusão: quem disser que uma sobrevive sem a outra não está no seu perfeito juízo. pp. 89-108. Portugal: Porto Editora, 2003.

LOPES, Betania Jacob Stange. Programa de transição para a vida adulta de jovens com deficiência intelectual em ambiente universitário. Tese de Doutorado do Programa de Pós-Graduação em Educação Especial. São Carlos: UFSCar, 2016.

LUECKING, Richard. Emprego Customizado: empregando pessoas com necessidades especiais. Workshop na Universidade do Estado do Rio de Janeiro, 2012.

MASCARO, Cristina Angélica Aquino de Carvalho. Planos de Ensino Individualizados: Estratégia para Educação de Alunos com Deficiência Intelectual. Tese do Curso de Doutorado do Programa de Pós-Graduação em Educação da Universidade do Estado do Rio de Janeiro, 2017.

MARTIN-LUECKING, Debra. Plano de Transição e Programa de Ensino Individualizado - PEI. Palestra ministrada na Universidade do Estado do Rio de Janeiro, 2012.

PLETSCH, Márcia Denise; GLAT, Rosana. Plano Educacional Individualizado (PEI): um diálogo entre práticas curriculares e processos de avaliação escolar. In: GLAT, Rosana; PLETSCH, Márcia Denise (Org.). Estratégias Educacionais diferenciadas 
http://dx.doi.org/10.5902/1984686X35721

para alunos com necessidades especiais. 1. ed. Rio de Janeiro: EdUERJ, 2013. v. 1, p. 17-34.

REBELO, Andressa Santos; KASSAR, Mônica de Carvalho Magalhães. Indicadores

Educacionais de matrículas de alunos com deficiência no Brasil (1974-2014). Revista Estudos em Avaliação Educacional. v. 29, n. 70, p. 276-307. São Paulo, 2018, Disponível em: http://publicacoes.fcc.org.br/ojs/index.php/eae/article/view/3989/3576 Data de acesso 04/11/2018.

REDIG, Annie Gomes. Perfil Pessoal Positivo: estratégia para favorecer a inserção da pessoa com deficiência intelectual no mercado de trabalho. In: V Congresso Brasileiro de Educação Especial e VII Encontro Nacional dos Pesquisadores da Educação Especial. p. 1315-1330. São Carlos: UFSCar, 2012.

REDIG, Annie Gomes. Inclusão da pessoa com deficiência intelectual no mercado de trabalho rompendo paradigmas. In: VII Congresso Brasileiro Multidisciplinar de Educação Especial e VIII Encontro da Associação Brasileira de Pesquisadores em Educação Especial. p. 1-10. Londrina, 2013. p. 1-10.

REDIG, Annie Gomes. Aplicação e análise de um programa customizado para a inclusão de jovens com deficiência intelectual em atividades laborais. Tese do Programa de Pós-Graduação em Educação da Universidade do Estado do Rio de Janeiro, 2014.

REDIG, Annie Gomes. Inserção profissional de jovens e adultos com deficiência intelectual. Curitiba: Editora Appris, 2016.

REDIG, Annie Gomes; GLAT, Rosana. Programa educacional especializado para capacitação e inclusão no trabalho de pessoas com deficiência intelectual. Ensaio. v. 25, p. 330-355, 2017. Disponível em: http://www.scielo.br/pdf/ensaio/v25n95/18094465-ensaio-S0104-40362017002500869.pdf Data de acesso 10/10/2018.

REDIG, Annie Gomes; MASCARO, Cristina Angélica Aquino de Carvalho; ESTEF, Suzanli. Estudantes com deficiência intelectual: perspectivas para a vida adulta e o plano individual de transição. In: VII Congresso Brasileiro de Educação Especial. São Carlos: 2016.

RIAÑO-GALÁN, Ana; RODRÍGUEZ-MARTíN, Alejandro; GARCÍA-RUÍZ, Rosa; ÁLVAREZ-ARREGUI, Emilio. A transição a vida ativa de pessoas com deficiência: expectativas familiares e capacidade de ajuste ao trabalho. Revista Brasileira de Educação Especial, v. 20, n. 2, p. 283-302, Marília, 2014. Disponível em: http://www.scielo.br/pdf/rbee/v20n2/10.pdf Data de acesso 9/05/2017. 
SORIANO, Victoria. Planos individuais de transição: apoiar a transição da escola para o emprego. European Agency for Development in Special Needs Education, 2006.

TRAINOR, Audrey. Transition by design: improving equity and outcomes for adolescents with disabilities. Teachers College Press, Columbia University, New York, 2017.

VALLE, Jan W.; CONNOR, David J. Ressignificando a deficiência: da abordagem social às práticas inclusivas na escola. Porto Alegre: AMGH, 2014.

\section{Correspondência}

Annie Gomes Redig - Universidade do Estado do Rio de Janeiro, R. São Francisco Xavier, 524. CEP: 20550-900, Rio de Janeiro, Rio de Janeiro, Brasil.

http://orcid.org/0000-0002-1825-0097

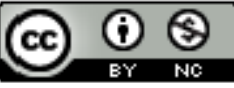

This work is licensed under a Creative Commons Attribution-NonCommercial 4.0 International (CC BY-NC 4.0) 